\title{
COMPORTAMENTO INGESTIVO DE CORDEIROS TEXEL E IDEAL ALIMENTADOS COM CASCA DE SOJA
}

\author{
INGESTIVE BEHAVIOR OF LAMBS TEXEL AND IDEAL FED SOYBEAN HULLS
}

\author{
Carvalho, S..$^{1 *}$; Dias, F.D.1; Pires, C.C. ${ }^{1}$; Brutti, D.D. ${ }^{1}$; Lopes, J.F.1; Santos, D. ${ }^{1}$; \\ Barcelos, R.D. ${ }^{1 ;}$ Macari, S. ${ }^{1}$; Wommer, T.P. ${ }^{1}$ e Griebler, L. ${ }^{1}$
}

\begin{abstract}
${ }^{1}$ Departamento de Zootecnia. Universidade Federal de Santa Maria. Santa Maria, RS. Brasil. *scarvalhoufsm@hotmail.com
\end{abstract}

\section{PaLAVRAS CHAVE ADICIONAIS}

Confinamento. Eficiência alimentar. Refeição. Ruminação.

\section{RESUMO}

O presente experimento, conduzido no laboratório de ovinocultura da Universidade Federal de Santa Maria, teve como objetivo avaliar o comportamento ingestivo de cordeiros das raças Texel e Ideal, terminados em confinamento com dietas contendo diferentes teores de casca de soja em substituição da silagem de sorgo. Foram utilizados 40 cordeiros machos não castrados, sendo 20 provenientes da raça Texel e 20 da raça Ideal, desmamados aproximadamente aos 50 dias e confinados em baias individuais, distribuídos aleatoriamente em quatro grupos de acordo com o nível de inclusão de casca de soja na dieta: $0 \%$, $33,5 \%, 66,5 \%$ e $100 \%$ de casca de soja em substituição a silagem de sorgo. O tempo despendido em atividades de alimentação, tempo de mastigação total e o tempo gasto por refeição diminuíram linearmente, enquanto que o período de ócio e a eficiência de alimentação e de ruminação aumentaram linearmente, com o aumento do nível de substituição de silagem de sorgo por casca de soja. Cordeiros da raça Texel permaneceram por mais tempo em atividades de ruminação e de mastigação total, gastaram mais tempo por refeição, permaneceram menos tempo em ócio e apresentaram menor eficiência de ruminação quando comparados com cordeiros da raça Ideal, quando confinados em fase de terminação.

\section{SUMMARY}

This experiment was conducted in the laboratory of sheep-raising of the Federal University

\section{AdDitionAl KEYWORDS}

Feedlot. Feeding efficiency. Meal. Ruminating. of Santa Maria aiming to evaluate the ingestive behavior of sheep breeds Texel and Ideal, finished in feedlot with diets containing different levels of soybean hulls in place of sorghum silage. Forty male uncastrated lambs were used, 20 from the Texel breed and 20 from Ideal breed, weaned approximately at 50 days and housed in individual pens were randomly divided into four groups according to the level of inclusion of soybean hulls in the diet: $0 \%, 33.5 \%, 66.5 \%$ and $100 \%$ of soybean hulls in replacement of sorghum silage. The time spent in feed activities, chewing time and the total time spent per meal decreased linearly, while the period of idleness and feeding efficiency of rumination increased linearly with increasing level of sorghum silage substitution by soybean hulls. Texel lambs remained more time on rumination activities and total chewing, spent more time per meal, spent less time in idleness and showed less rumination efficiency when compared with Ideal lambs when confined in the finishing phase.

\section{INTRODUÇÃO}

Atualmente, visando uma maior rentabilidade, a pecuária ovina esta buscando alternativas de alimentação que sejam adequadas do ponto de vista nutricional e ao mesmo tempo viáveis do ponto de vista financeiro. Tendo em vista esta busca, a grande variedade de alimentos passíveis de utilização, que surgem como alternativas 
têm suas influencias no comportamento ingestivo dos animais, tornando-se necessário conhecermos este comportamento para que possa ser otimizado o uso destes alimentos.

Os diferentes alimentos passíveis de utilização na alimentação dos ruminantes causam diferenças no comportamento ingestivo dos animais, interferindo nas atividades de alimentação, ruminação e ócio, que quando interpretadas, juntamente com outros fatores, nos dão condições de avaliar se este alimento fornecido encontra-se adequado do ponto de vista nutricional. Conforme Cardoso et al. (2006), o estudo do comportamento ingestivo dos animais é uma ferramenta de grande importância na avaliação das dietas, pois possibilita ajustar o manejo alimentar dos animais para a obtenção de melhor desempenho produtivo.

$\mathrm{O}$ teor de fibra em detergente neutro (FDN) contido nos alimentos e o tamanho de partícula são importantes fatores que influenciam no comportamento ingestivo dos animais. Quanto maior for a quantidade de FDN, e/ou o maior tamanho de partícula, maior será o tempo despendido em atividades de mastigação (alimentação e ruminação) e menor o tempo de ócio, o que pode influenciar a capacidade de ingestão de alimentos.

Entre os alimentos que se encontram como alternativa para serem utilizados na alimentação de cordeiros na fase de terminação encontra-se a casca de soja, um subproduto obtido da extração do óleo de soja e da produção de biocombustível. Zambom et al. (2001), citam que a casca de soja apresenta alto valor nutricional e, apesar de apresentar altos teores de FDN e FDA, esses são de alta digestibilidade. Esse aspecto é importante, pois pode permitir uma maior ingestão diária de matéria seca, e consequentemente de nutrientes, quando a casca de soja é utilizada como fonte de fibra em substituição total ou parcial ao alimento volumoso da dieta.

Contudo, Grant (1997) afirmou que a
FDN fisicamente efetiva (fração do alimento que estimula a atividade de mastigação) da casca de soja é menor que a FDN proveniente de uma fonte de forragem. Em estudo realizado por Morais et al. (2006), os autores constataram que a adição da casca de soja ocasiona redução na atividade de mastigação (devido ao menor tamanho de partícula, ou seja, menor fibra fisicamente efetiva), mas quantidade de fibra potencialmente digestível é um fator que compensa a menor produção de saliva, pois promove padrão de fermentação semelhante ao de forragem, contribuindo, desta forma, para manter o $\mathrm{pH}$ ruminal e não prejudicar a digestibilidade dos nutrientes. Os mesmos autores concluíram também que o uso de até $37,5 \%$ de casca de soja em substituição ao feno aumenta o consumo diário de matéria seca digestível e é benéfico ao desempenho de ovinos. Neste mesmo estudo foi constatado que a adição de casca de soja reduz o tempo de ingestão, ruminação e mastigação total (em minutos por dia, minutos por grama de matéria seca e minutos por grama de FDN), mas não prejudica a digestibilidade aparente dos nutrientes no trato digestório total.

Outro fator importante a ser considerado no confinamento de ovinos é o grupo racial. Cordeiros de raças especializadas para a produção de carne, como a raça Texel, tem sido freqüentemente utilizados em sistemas de confinamento visando a obtenção de carne ovina de qualidade. Contudo, na região Sul do Brasil ainda existe uma base laneira, com um grande contingente do rebanho de ovinos da raça Ideal, onde os cordeiros têm sido destinados ao abate e para o mercado consumidor. Nesse sentido, estudos que avaliem o comportamento ingestivo de animais da raça Texel em relação aos da raça Ideal, são importantes que sejam conduzidos.

Objetivou-se com esse trabalho avaliar o comportamento ingestivo de cordeiros das raças Texel e Ideal, terminados em confinamento e alimentados com diferentes 
teores de casca de soja, como alimento volumoso, em substituição da silagem de sorgo da dieta.

\section{MATERIALE MÉTODOS}

O experimento foi conduzido no Laboratório de Ovinocultura do Departamento de Zootecnia da Universidade Federal de Santa Maria (UFSM), RS, no período de outubro a dezembro de 2010. A UFSM localiza-se na região, fisiograficamente denominada Depressão Central, possui altitude de 95 m, latitude de $29^{\circ} 43^{\prime}$ Sul e longitude de $53^{\circ} 42^{\prime}$ Oeste, segundo a classificação de Köppen (Moreno, 1961).

Foram utilizados 40 cordeiros machos não castrados, sendo 20 provenientes da raça Texel e 20 da raça Ideal, distribuídos em delineamento experimental inteiramente casualizado, em esquema fatorial $4 \times 2$ (quatro dietas e dois grupos genéticos) e cinco repetições. Os cordeiros foram desmamados aproximadamente aos 50 dias e confinados em baias individuais, distribuídos aleatoriamente em quatro grupos de acordo com o nível de inclusão de casca de soja na dieta: $0 \%, 33,5 \%, 66,5 \%$ e $100 \%$ de casca de soja em substituição a silagem de sorgo. Os animais foram confinados em baias individuais, totalmente cobertas, com piso ripado, aproximadamente $1,0 \mathrm{~m}$ acima do solo, com dimensão de $2 \mathrm{~m}^{2}$ por animal. Todas as baias eram providas de comedouros e bebedouros individuais, onde foi fornecida a alimentação e a água para os cordeiros.

Os cordeiros foram desmamados quando atingiram 50 dias de idade em média, e então distribuídos nos tratamentos. O volumoso utilizado foi silagem de sorgo (Sorghum bicolor (L.) Moench), cortado com aproximadamente $32 \%$ de matéria seca e idade da planta em torno de 120 dias, e/ou casca de soja e o concentrado era constituído por milho desintegrado, farelo de soja e mistura mineral (tabela I). As dietas foram formuladas para serem isoprotéicas, de acordo com o NRC (1985), sendo que a relação entre silagem de sorgo e casca de soja variou de acordo com o tratamento, em base da matéria seca (MS), de maneira a se atingir o nível de casca de soja como alimento volumoso, pretendido para a dieta experimental (tabela II).

O alimento foi fornecido, ad libitum, duas vezes ao dia, sendo os horários de arraçoamento às 8:00 e 17:00 horas. A quantidade oferecida foi ajustada em função da sobra observada diariamente, sendo que esta deveria ser $10 \%$ da quantidade oferecida no dia anterior, de modo a garantir o consumo voluntário máximo dos animais.

O período experimental foi precedido de um período de 10 dias para adaptação dos animais as condições de instalações, alimentação e manejo. O ensaio de ali-

Tabela I. Composição química (\%MS) dos alimentos utilizados na formulação das dietas experimentais.(Dry matter chemical composition of ingredients used in the experimental diets).

\begin{tabular}{lccccc}
\hline & $\begin{array}{c}\text { Silagem } \\
\text { sorgo }\end{array}$ & $\begin{array}{c}\text { Casca } \\
\text { soja }\end{array}$ & $\begin{array}{c}\text { Milho } \\
\text { quebrado }\end{array}$ & $\begin{array}{c}\text { Farelo } \\
\text { soja }\end{array}$ & $\begin{array}{c}\text { Calcário } \\
\text { calcico }\end{array}$ \\
\hline MS & 25,87 & 89,69 & 89,32 & 87,80 & 100 \\
MO & 95,64 & 95,37 & 98,78 & 93,29 & - \\
PB & 4,90 & 11,41 & 7,63 & 48,89 & - \\
EE & 1,51 & 2,44 & 10,97 & 4,19 & - \\
FDN & 67,25 & 65,00 & 8,80 & 12,30 & - \\
CHT & 89,03 & 81,52 & 80,18 & 40,21 & - \\
CNE & 21,78 & 16,52 & 71,38 & 27,91 & - \\
CIN & 4,56 & 4,63 & 1,22 & 6,71 & - \\
NDT & 57,23 & 68,77 & 87,24 & 81,54 & - \\
EL & 1,28 & 1,56 & 2,02 & 1,88 & - \\
Ca & 0,34 & 0,44 & 0,02 & 0,3 & 34 \\
P & 0,17 & 0,14 & 0,21 & 0,69 & 0,02 \\
\hline
\end{tabular}

$\mathrm{MS}=$ matéria seca; $\mathrm{MO}=$ matéria orgânica; $\mathrm{PB}=$ proteína bruta; $\mathrm{EE}=$ extrato etéreo; $\mathrm{FDN}=$ fibra em detergente neutro; $\mathrm{CHT}=$ carboidratos totais; $\mathrm{CNE}=$ carboidratos não estruturais; CIN= cinzas; NDT= nutrientes digestíveis totais (Valadares Filho et al., 2006); $E L=$ energia líquida $(E L=(0,0245 \times$ \%NDT) - 0,12, segundo Moe e Tyrrel, 1976,®). 
mentação iniciou após o período de adaptação, tendo duração total de 70 dias, quando o último cordeiro foi abatido. $\mathrm{O}$ peso de abate foi pré-estabelecido em $32 \mathrm{~kg}$ de peso vivo para os animais da raça Texel e $27 \mathrm{~kg}$ de peso vivo para os animais da raça Ideal, correspondendo $60 \%$ do peso vivo a maturidade das suas mães, segundo recomendação de Butterfield (1988).

Para determinação do consumo de MS e de FDN, diariamente foram coletadas amostras das sobras (10\% do peso total) e dos alimentos oferecidos, sendo feitas amostras compostas a cada 21 dias. Essas foram acondicionadas em sacos plásticos

Tabela II. Proporção dos ingredientes (\%MS) e composição bromatológica das dietas experimentais. (Proportion of ingredients and chemical composition of experimental diets).

\begin{tabular}{|c|c|c|c|c|}
\hline & \multicolumn{4}{|c|}{$\%$ de casca de soja } \\
\hline & 0 & 33,5 & 66,5 & 100 \\
\hline \multicolumn{5}{|c|}{ Proporção dos ingredientes } \\
\hline Silagem de sorgo & 50,00 & 33,25 & 16,75 & 0,00 \\
\hline Casca de soja & 0,00 & 16,75 & 33,25 & 50,00 \\
\hline Milho quebrado & 22,96 & 25,63 & 28,27 & 30,95 \\
\hline Farelo de soja & 26,18 & 23,53 & 20,92 & 18,27 \\
\hline Calcário calcítico & 0,86 & 0,84 & 0,81 & 0,78 \\
\hline \multicolumn{5}{|c|}{ Composição bromatológica (\%MS) } \\
\hline MS & 57,29 & 68,02 & 78,58 & 89,31 \\
\hline MO & 95,68 & 95,82 & 95,95 & 96,08 \\
\hline PB & 17,00 & 17,00 & 17,00 & 17,00 \\
\hline EE & 4,37 & 4,71 & 5,04 & 5,38 \\
\hline FDN & 38,87 & 38,40 & 37,94 & 37,47 \\
\hline $\mathrm{CHT}$ & 73,45 & 73,27 & 73,10 & 72,92 \\
\hline CNE & 34,59 & 34,87 & 35,16 & 35,45 \\
\hline $\mathrm{CIN}$ & 4,32 & 4,18 & 4,05 & 3,92 \\
\hline NDT & 69,99 & 72,09 & 74,17 & 76,28 \\
\hline EL & 1,60 & 1,65 & 1,70 & 1,75 \\
\hline $\mathrm{Ca}$ & 0,55 & 0,55 & 0,55 & 0,55 \\
\hline $\mathrm{P}$ & 0,31 & 0,30 & 0,28 & 0,26 \\
\hline
\end{tabular}

$M S=$ matéria seca; $M O=$ matéria orgânica; $P B=$ proteína bruta; $\mathrm{EE}=$ extrato etéreo; $\mathrm{FDN}=$ fibra em detergente neutro; $\mathrm{CHT}=$ carboidratos totais; $\mathrm{CNE}=$ carboidratos não estruturais; $\mathrm{CIN}=$ cinzas; NDT= nutrientes digestíveis totais; EL= energia líquida. identificados e armazenadas em freezer a $-10{ }^{\circ} \mathrm{C}$, para posteriores análises laboratoriais.

As amostras de alimentos e sobras foram pré-secas em estufa ventilada a $55^{\circ} \mathrm{C}$ por aproximadamente 72 horas e, posteriormente, moídas em moinho tipo Willey com peneira de $1 \mathrm{~mm}$. A determinação dos teores de matéria seca (MS) foi realizada por secagem em estufa a $105^{\circ} \mathrm{C}$ durante 24 horas, e de cinzas por incineração em mufla a $550^{\circ} \mathrm{C}$ por duas horas (Silva e Queiroz, 2002). A fibra em detergente neutro (FDN) e fibra em detergente ácido (FDA) foram realizadas segundo metodologia descrita por Senger et al. (2008). O teor de nitrogênio total (N) foi determinado pelo método Kjeldahl (AOAC, 1995), modificado segundo Kozloski et al. (2003). Para conversão dos valores de N em proteína bruta (PB) foi utilizado o fator de correção de 6,25. A determinação dos teores de extrato etéreo (EE) foi realizada em sistema de refluxo de éter (Soxtherm, Gerhardt, Alemanha) a $180^{\circ} \mathrm{C}$ durante duas horas. Os teores de carboidratos totais (CHT) foram calculados segundo Sniffen et al. (1992), em que CHT $(\%)=100-(\% P B+\% E E+$ \%CIN), e os teores de carboidratos nãofibrosos (CNF), pela diferença de CHT-FDN.

Os animais foram tratados com vermífugo no início do experimento e o controle posterior de endoparasitos foi realizado através do método FAMACHA de Malan e Van Wyk (1992). Os animais foram também vacinados contra carbúnculo sintomático, gangrena gasosa e enterotoxemia.

O comportamento ingestivo foi determinado mediante observação individual visual dos animais, durante 24 horas, a intervalos de 10 minutos para determinar-se o tempo despendido em alimentação, ruminação e ócio. Na observação noturna dos animais, o ambiente foi mantido com iluminação artificial.

Os resultados referentes aos fatores do comportamento ingestivo foram obtidos segundo Carvalho et al. (2006), utilizandose as seguintes equações: 
$E A L_{M S}=C M S / T A L ;$

$E A L_{F D N}=C F D N / T A L ;$

em que

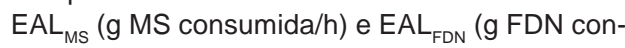
sumida/h)= eficiência de alimentação;

CMS $(\mathrm{g})=$ consumo diário de matéria seca; CFDN $(\mathrm{g})=$ consumo diário de FDN;

$\mathrm{TAL}=$ tempo gasto em alimentação diariamente.

\section{$E R U_{M S}=C M S / T R U ;$}

$E R U_{\mathrm{FDN}}=\mathrm{CFDN} / \mathrm{TRU}$;

em que

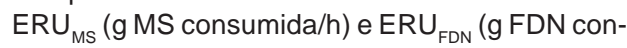
sumida/h)= eficiência de ruminação;

TRU $(\mathrm{h} / \mathrm{dia})=$ tempo de ruminação.

$T M T=T A L+T R U ;$

em que

TMT $(\mathrm{min} / \mathrm{dia})=$ tempo de mastigação total.

O número de refeições foi obtido pelo número de vezes que os cordeiros se encontravam no comedouro em atividade de alimentação. O tempo por refeição foi obtido dividindo-se o tempo total de alimentação pelo número de refeições.

O delineamento experimental utilizado foi o inteiramente casualizado, em esquema fatorial $2 \times 4$ (duas raças x 4 níveis de substituição de silagem de sorgo por casca de soja), com cinco repetições por tratamento. Foi testado o efeito do nível de casca de soja, da raça e da interação nível x raça, através de análise de variância e teste $\mathrm{F}$, a nível de 5 \% de significância. O efeito do nível de casca foi analisado através de análise de regressão. As análises foram realizadas utilizando-se o pacote estatístico SAS (2004). O modelo matemático utilizado foi:

$$
Y_{i j k}=m+a_{i}+a ̂ j+\left(a_{x} \hat{a}\right) i j+e_{i j k}
$$

$Y_{i, j k}=$ Observação referente ao animal k, do nível de substituição do volumoso por casca de soja i e da raça j;

m= Média geral das observações; $a_{i}=$ Efeito do nível de substituição do volumoso por casca de soja i (i=1, 2, 3, 4);

$\hat{A} j=$ Efeito da raça $j(j=1,2)$;

$a_{x} a ̂=$ Efeito da interação;

$\mathrm{e}_{\mathrm{ijk}}=$ Erro aleatório associado a cada observação.

\section{RESULTADOSEDISCUSSÃO}

Não foi observada interação para nenhuma das variáveis analisadas entre a raça e o nível de casca de soja em substituição a silagem de sorgo. Portanto, os dados foram analisados de forma independente.

Não foi observado efeito do nível de inclusão de casca de soja na dieta sobre o tempo despendido em alimentação pelos animais. Contudo, verificou-se redução linear $(p<0,01)$ do tempo de ruminação, e como consequência, redução no tempo de mastigação total (alimentação + ruminação) (tabela III). Esse resultado pode ser explicado pelo menor tamanho de partícula da casca de soja quando comparada a silagem de sorgo e rápida taxa de passagem ruminal desta. Segundo Poppi et al. (1980), a FDN fisicamente efetiva (FDNfe) que está associada as características físicas da fibra (tamanho de partícula) que afetam a atividade de ruminação, pode ser determinada através da proporção de partículas de alimentos retidas em peneira com porosidade menores que $1,18 \mathrm{~mm}$, sendo essas capazes de estimular a ruminação. O tamanho de partícula da casca de soja era inferior ao da silagem de sorgo, sendo que esse aspecto pode explicar o resultado obtido em relação ao comportamento de ruminação e de tempo total de mastigação.

O tempo de ócio aumentou linearmente como uma consequência da redução do tempo de ruminação, uma vez que o tempo de alimentação não foi influenciado pela dieta.

Resultado semelhante ao desse estudo foi obtido por Silva et al. (2009), os quais testaram o efeito de diferentes fontes de fibra em dietas a base de palma forrageira sobre o comportamento ingestivo de ovinos. Os tratamentos experimentais consistiam 
de uma ração completa formada por palma forrageira (Nopalea cochellinifera Salm Dyck), concentrado e diferentes fontes de fibra (feno de Tifton, casca de soja, caroço de algodão, casca de soja mais feno de Tifton e caroço de algodão mais feno de Tifton). Os autores observaram que o tempo de ruminação foi menor $(\mathrm{p}<0,05)$ quando a casca de soja foi a fonte de fibra, demonstrando que este subproduto, embora apresente teor de FDN semelhante ao de forragens, possui estímulo a ruminação restrito, devido ao tamanho reduzido de partículas.

Em outro estudo, Morais et al. (2006), testando o efeito da substituição de feno de coastcross por casca de soja em uma proporção que variou de $0 \%$ a 37,5 \% da dieta total, verificaram efeito linear decrescente nos tempos de ruminação e de mastigação a medida que aumentou o nível de casca de soja na dieta, observando a mesma tendência verificada no presente trabalho. Esses autores também verificaram redução linear no tempo de ingestão, aspecto esse não verificado no presente estudo.

Os valores médios da eficiência de alimentação e de ruminação, da MS e da FDN, apresentaram comportamento linear crescente, em função da elevação do teor de casca de soja na dieta (tabela III). Em relação à eficiência de alimentação, como não houve efeito da inclusão da casca de soja sobre o tempo despedido em alimentação, em minutos por dia, o aumento linear no consumo de matéria seca e de fibra em detergente neutro fez com que os cordeiros que receberam níveis mais elevados de casca de soja na dieta ingerissem uma maior quantidade de MS e de FDN em tempos semelhantes de

Tabela III. Efeito do nível de substituição de silagem de sorgo por casca de soja sobre o comportamento ingestivo de cordeiros confinados. (Effect of the substitution of sorghum silage by soybean hulls on the ingestive behavior of feedlot lambs).

\begin{tabular}{|c|c|c|c|c|c|c|c|}
\hline & & $\%$ de ca & ca de so & & & & \\
\hline & 0 & 33,5 & 66,5 & 100 & Equação de regressão & $\mathrm{R}^{2}$ & $p>F$ \\
\hline CMS (kg/dia) & 0,697 & 0,840 & 0,889 & 0,930 & $v=0,729+0,002 \mathrm{CS}$ & 0,41 & 0,0001 \\
\hline CFDN (kg/dia) & 0,217 & 0,279 & 0,326 & 0,344 & $v=0,228+0,001 C S$ & 0,61 & 0,0001 \\
\hline Alim. (min./dia) & 223,33 & 247,00 & 207,78 & 226,00 & $v=226,58$ & - & 0,6780 \\
\hline nin./dia) & 356,67 & 347,0 & 214,2 & 156, & $v=3$ & 0,56 & 0,0001 \\
\hline hin./dia) & 580,00 & 594,00 & 422,22 & 382,00 & $v=611$ & 0,50 & 0,0001 \\
\hline Ócio (min./dia) & 841,11 & 828,00 & 974,44 & 1019,00 & $+2,059 \mathrm{CS}$ & 0,47 & 0,0001 \\
\hline Outras (min./dia) & 18,88 & 18,00 & 43,33 & 39,00 & $+0,256 \mathrm{CS}$ & 0,14 & 0,0214 \\
\hline $\mathrm{EAL}_{\mathrm{MS}}(\mathrm{g} \mathrm{MS} / \mathrm{h})$ & 189,32 & 222,71 & 273,73 & 249,26 & $v=199,555+0,674 C S$ & 0,17 & 0,0089 \\
\hline$E A L_{F D N}(g F D N / h)$ & 58,70 & 74,35 & 100,78 & 92,12 & $v=62,625+0,372 \mathrm{CS}$ & 0,31 & 0,0002 \\
\hline $\mathrm{ERU}_{\mathrm{MS}}(\mathrm{g} \mathrm{MS} / \mathrm{h})$ & 119,38 & 149,24 & 290,51 & 413,37 & $v=87,327+3,101 \mathrm{CS}$ & 0,60 & 0,0001 \\
\hline$E R U_{F D N}^{m}(g F D N / h)$ & 37,16 & 49,68 & 105,75 & 153,03 & $v=24,967+1,222 \mathrm{CS}$ & 0,63 & 0,0001 \\
\hline Nref. & 8,89 & 10,80 & 10,00 & 12,90 & $v=8,976+0,034 C S$ & 0,16 & 0,0113 \\
\hline Tref. (min) & 26,15 & 23,49 & 21,74 & 17,86 & $v=26,316-0,080 \mathrm{CS}$ & 0,31 & 0,0003 \\
\hline
\end{tabular}

CMS = consumo de matéria seca; $\mathrm{CFDN}=$ consumo de fibra em detergente neutro; Alim.= tempo de alimentação; Rum.= tempo de ruminação; TMT= tempo de mastigação total; Ócio= tempo em ócio; Outras= tempo em outras atividades; $E A L_{M S}=$ eficiência de alimentação para matéria seca; $E A L_{F D N}=$ eficiência de alimentação para fibra em detergente neutro; $\mathrm{ERU}_{\mathrm{MS}}=$ eficiência de ruminação para matéria seca; $\mathrm{ERU}_{\mathrm{FDN}}=$ eficiência de ruminação para fibra em detergente neutro; Nref.= número de refeições; Tref.= tempo por refeição. CS= nível de substituição do volumoso da dieta por casca de soja.

Archivos de zootecnia vol. 63, núm. 241, p. 60. 
alimentação. Isso explica a melhoria na eficiência de alimentação, expressa em g, de MS ou de FDN, por hora. Já em relação a eficiência de ruminação, o aumento linear verificado também se deve a uma maior quantidade de MS e de FDN ingerida com o aumento do teor de casca de soja na dieta. Como houve redução no tempo despedido em ruminação, os animais dos tratamentos com maior teor de casca de soja gastaram menos tempo ruminando uma maior quantidade de MS ou de FDN ingerida, o que explica o resultado obtido.

Carvalho et al. (2006) avaliaram o comportamento ingestivo de cabras da raça Alpina alimentadas com dietas contendo diferentes níveis de fibra em detergente neutro oriunda da forragem (feno de Tifton85), e verificaram que com o aumento do teor de fibra oriunda da forragem na dieta, houve redução linear no consumo de matéria seca, levando a um aumento linear da eficiência de alimentação e de ruminação, o que corrobora os resultados obtidos. Da mesma forma Hübner et al. (2008), utilizando proporções crescentes de volumoso (silagem de milho) na dieta de ovelhas em lactação, verificaram redução na eficiência de alimentação e de ruminação, o que também está de acordo com o presente estudo.

Observa-se que ocorreu efeito crescente do nível de casca de soja sobre o número de refeições (tabela III). O menor tamanho de partícula e a maior digestibilidade da FDN da casca de soja em relação a silagem de sorgo explica esse comportamento, provavelmente devido a um aumento da taxa de passagem e redução do tempo de permanência do alimento no trato digestivo, permitiram uma maior capacidade de ingestão diária de alimento (observada no aumento do consumo de MS apresentado na tabela III), o que fez com que os animais procurassem mais vezes, durante o dia, alimento no comedouro.

Já o tempo gasto por refeição diminuiu a medida que aumentou a proporção de casca de soja na dieta, podendo esse resultado também ser explicado pelo menor tamanho de partícula do alimento, fazendo com que uma maior quantidade de alimento fosse ingerida por bocado dos animais. Além disso, com o aumento da casca de soja, houve elevação da concentração de energia na dieta (tabela II), proporcionando saciedade dos animais (regulação fisiológica do consumo) em um menor tempo. Resultado semelhante foi obtido por Bürger et al. (2000), que realizou um estudo para avaliar os efeitos de diferentes níveis de concentrado em bezerros da raça holandês e verificou que o aumento da proporção de concentrado na dieta e como consequência de energia, proporcionou redução linear do tempo gasto por atividade de refeição.

Não houve diferença significativa, entre as raças, para o tempo despendido para alimentação e outras atividades (tabela IV). Contudo, o tempo despendido com ruminação e, conseqüentemente, de mastigação total, foi superior nos cordeiros da raça Texel em relação aos da raça Ideal. O maior consumo de matéria seca e de FDN dos cordeiros da raça Texel levou a uma maior necessidade de processamento do alimento em atividades de ruminação dos animais dessa raça, aspecto esse que explica o resultado obtido. Já o tempo em que os animais permaneceram em ócio apresentou comportamento inverso. O maior consumo de matéria seca dos cordeiros da raça Texel também pode explicar a superioridade desses animais quando comparados aos da raça Ideal em relação ao tempo gasto por refeição, pois não houve diferença entre as raças para o número de refeições.

Em estudo com cordeiros cruza Ile de France x Texel, machos não castrados, confinados e abatidos quando atingiram $30 \mathrm{~kg}$ de peso vivo, Cardoso et al. (2006) testaram quatro níveis de FDN na dieta (25\%, $31 \%$, 37 \% e 43 \%), não tendo encontrado diferenças significativas entre os tratamentos para as variáveis de comportamento ingestivo avaliadas. Os valores médios observados por esses autores, em termos 
percentuais, do total de atividades de comportamento diária, foram 14,28 \% para alimentação, 33,55 \% para ruminação, 51,71 \% para ócio e 0,46 \% para outras atividades. Esses resultados são próximos aos do presente estudo que foram para alimentação de $15,73 \%$, porém superiores para ruminação que foram de 18,59 \% e inferiores para ócio e outras atividades, cujos valores obtidos foram de 63,61\% e 2,07\%, respectivamente. Os distintos tempos de ruminação explicam as diferenças obtidas entre os estudos.

Embora tenha sido verificada diferença entre raças para o consumo de matéria seca, não verificada diferença para a eficiência de

Tabela IV. Efeito da raça sobre o comportamento ingestivo de cordeiros confinados. (Effect of race on the feeding behavior of feedlot lambs).

\begin{tabular}{|c|c|c|c|c|}
\hline & $\mathrm{Ra}$ & ç̧a & & \\
\hline & Ideal & Texel & Média & $p>F$ \\
\hline CMS (kg/dia) & $0,796^{b}$ & $0,887^{a}$ & 0,843 & 0,001 \\
\hline CFDN (kg/dia) & $0,281^{b}$ & $0,305^{a}$ & 0,293 & 0,020 \\
\hline Alim. (min./dia) & 226,84 & 226,32 & 226,58 & 0,937 \\
\hline Rum. (min./dia) & $224,21^{b}$ & $311,05^{a}$ & 267,63 & 0,000 \\
\hline TMT (min./dia) & $451,05^{b}$ & $537,37^{a}$ & 494,21 & 0,002 \\
\hline Ócio (min./dia) & $953,16^{a}$ & $878,95^{b}$ & 916,05 & 0,007 \\
\hline Outras (min./dia) & 35,79 & 23,68 & 29,74 & 0,227 \\
\hline $\mathrm{EAL}_{\mathrm{MS}}(\mathrm{g} \mathrm{MS} / \mathrm{h})$ & 219,81 & 247,93 & 233,87 & 0,070 \\
\hline $\mathrm{EAL}_{\mathrm{FDN}}(\mathrm{g} \mathrm{FDN} / \mathrm{h})$ & 77,76 & 85,40 & 81,58 & 0,138 \\
\hline$E R U_{M S}(g M S / h)$ & $282,49^{a}$ & $207,78^{b}$ & 245,13 & 0,033 \\
\hline$E R U_{F D N}(g F D N / h)$ & $101,88^{a}$ & $72,50^{\mathrm{b}}$ & 87,19 & 0,017 \\
\hline Nref. & 11,42 & 10,00 & 10,71 & 0,121 \\
\hline Tref. (min) & $20,42^{b}$ & $24,03^{a}$ & 22,23 & 0,012 \\
\hline $\begin{array}{l}\text { CMS= consumod } \\
\text { de fibra em dete } \\
\text { alimentação; Run } \\
\text { tempo de mastiga } \\
\text { Outras= tempo } \\
\text { eficiência de ali } \\
\text { EAL } \text { FDN }=\text { eficiênci }_{\text {detergente neutro }} \\
\text { para matéria seca; } \\
\text { para fibra em dete } \\
\text { refeições; Tref.= }\end{array}$ & $\begin{array}{l}\text { em outra } \\
\text { imentaçãc } \\
\text { ia de alim } \\
\text {;ERU } \\
\text {;ERU } \\
\text { ergente ne } \\
\text { tempo pc }\end{array}$ & $\begin{array}{l}\text { o para } \\
\text { nentação } \\
\text { eficiênci } \\
\text { eficiênci } \\
\text { eutro; Nre }\end{array}$ & $\begin{array}{l}\text { tempo en } \\
\text { lades; E } \\
\text { matéria } \\
\text { para fib } \\
\text { ia de rumi } \\
\text { ia de rum } \\
\text { ef.= núm }\end{array}$ & $\begin{array}{l}\text { nsumo } \\
\text { רpo de } \\
\text { TMT= } \\
\text { n ócio; } \\
\text { EL }_{\text {Ms }}= \\
\text { seca; } \\
\text { ora em } \\
\text { inação } \\
\text { inação } \\
\text { iero de }\end{array}$ \\
\hline
\end{tabular}

alimentação, expresso em g de MS ou g de FDN ingerida por hora (tabela IV). Esse resultado pode ser explicado pela similaridade observada em relação ao tempo despendido em alimentação e pela pouca diferença, em termos numérico, observada para consumo de matéria seca e de FDN. Em relação a eficiência de ruminação, expresso em g de MS ou g de FDN ruminada por hora, observa-se maior eficiência nos cordeiros da raça Ideal em relação aos da raça Texel. Embora os cordeiros da raça Ideal tenham ingerido uma menor quantidade diária de MS e FDN, e que tenham apresentado um menor tempo de ruminação, quando se calcula a eficiência de ruminação $\left(\mathrm{ERU}_{\mathrm{MS}}=\right.$ CMS/TRU ou ERU ${ }_{\mathrm{FDN}}=\mathrm{CFDN} / \mathrm{TRU}$ ), verifica-se superioridade nos cordeiros da raça Ideal.

Não houve diferença significativa para o número de refeições, porém, o tempo gasto por atividade de refeição foi maior nos cordeiros da raça Texel em relação aos da raça Ideal. O maior consumo diário de matéria seca dos cordeiros da raça Texel pode explicar esse resultado, já que não houve diferença em relação ao número de refeições.

\section{CONCLUSÕES}

A inclusão da casca de soja em substituição a silagem de sorgo na dieta de cordeiros confinados promove aumento do consumo diário de MS e de FDN e leva a diminuição das atividades de ruminação, do tempo total de mastigação diária e do tempo gasto por refeição. Além disso, promove aumento do período em que os animais se encontram em ócio, do número diário de refeições e da eficiência de alimentação e de ruminação, da MS e da FDN, da dieta. Portanto, pode-se recomendar a substituição de $100 \%$ da silagem de sorgo por casca de soja como fonte de volumoso na terminação de cordeiros em confinamento.

Cordeiros da raça Ideal, terminados em sistema de confinamento, gastam menos tempo em atividades de ruminação e de

Archivos de zootecnia vol. 63, núm. 241, p. 62. 
mastigação total, permanecem maior tempo em ócio, apresentam uma maior eficiência de ruminação da MS e da FDN, e gastam menos tempo por atividade de refeição quando

\section{BIBLIOGRAFIA}

AOAC. 1995. Official methods of analysis. $16^{\mathrm{a}} \mathrm{ed}$. AOAC. Washington, D.C. $1141 \mathrm{pp}$.

Bürger, P.J.; Pereira, J.C.; Queiroz, A.C.; Silva, J.F.C.; Valadares Filho, S.C.; Cecon, P.R. e Casali, A.D.P. 2000. Comportamento ingestivo em bezerros Holandeses alimentados com dietas contendo diferentes níveis de concentrado. Rev Bras Zootecn, 29: 236-242.

Butterfield, R.M. 1988. News concepts of sheep growth. Sydney. Sydney University Press. 168 pp.

Cardoso, A.R.; Carvalho, S.; Galvani, D.B.; Pires, C.C.; Gasperin, B.G. e Garcia, R.P.A. 2006. Comportamento ingestivo de cordeiros alimentados com dietas contendo diferentes níveis de fibra em detergente neutro. Ciênc Rural, 36: 604-609.

Carvalho, S.; Rodrigues, M.T.; Branco, R.H. e Rodrigues, C.A.F. 2006. Comportamento ingestivo de cabras Alpinas em lactação alimentadas com dietas contendo diferentes níveis de fibra em detergente neutro proveniente da forragem. Rev Bras Zootecn, 35: 562-568.

Grant, R.J. 1997. Interactions among forages and monforage fiber sources. J Dairy Sci, 80: 14381446.

Hübner, C.H.; Pires, C.C.; Galvani, D.B.; Carvalho, S.; Jochims, F.; Wommer, T.P. e Gasperin, B.G. 2008. Comportamento ingestivo de ovelhas em lactação alimentadas com dietas contendo diferentes níveis de fibra em detergente neutro. Ciênc Rural, 38: 1078-1084.

Kozloski, G. V.; Perottoni, J.; Ciocca, M.L.S.; Rocha, J.B.T.; Raiser, A.G. and Sanchez, L.M.B. 2003. Potential nutritional assessment of dwarf elephant grass (Pennisetum purpureum Schum. cv. Mott) by chemical composition, digestion and net portal flux of oxygen in cattle. Anim Feed Sci Tech, 104: 29-40.

Malan, F.S. and Van Wyk, J.A. 1992. The packed cell volum and color of the conjunctivae as aids for monitorin Haemonchus contortus infestations comparados com cordeiros da raça Texel, quando esses apresentam maturidades semelhantes em relação ao rebanho base dos quais foram originados.

in sheep. In: Biennial National Veterinary Congress. Grahamstown. South African metabolizable and net energy of feeds. International Symposium on Feed Composition, Animal Nutrient Requirements, and Computerization of Diets. Proceedings... Utah State University. Logan. pp. 232-237.

Morais, J.B. ; Susin, I.; Pires, A.V.; Mendes, C.Q.; Oliveira Junior, R.C. e Packer, I.U. 2006. Comportamento ingestivo de ovinos e digestibilidade aparente dos nutrientes de dietas contendo casca de soja. Pesqui Agropecu Bras, 41: 1157-1164.

Moe, P.W. and Tyrrel, H.F. 1976. Estimating metabolizable and net energy of feeds. International Symposium on Feed Composition, Animal Nutrient Requirements, and Computerization of Diets. Proceedings... Utah State University. Logan. pp. 232-237.

Moreno, J.A. 1961. Clima do Rio Grande do Sul. Porto Alegre. Secretaria da Agricultura. Porto Alegre $41 \mathrm{pp}$.

NRC. 1985. National Research Council. Nutrient requirements of sheep. $6^{\mathrm{a}}$ ed. National Academy Press. Washington, DC. 99 pp.

Poppi, D.P.; Norton, B.W.; Minson, D.J. and Hendricksen, R. E. 1980. The validity of the critical size theory for particles leaving the rumen. J Agr Sci, 94 : 275-280.

SAS. 2004. User's Guide. Statistical Analysis System Institute. Cary, North Carolina. 5135 pp. Senger, C.; Kozloski, G.V.; Bonnecarrère Sanchez, L.M.; Mesquita, F.R.; Alves, T.P. and Castagnino, D.S. 2008. Evaluation of autoclave procedures for fibre analysis in forage and concentrate feedstuffs. Anim Feed Sci Tech, 146: 169-174.

Silva, D.J. e Queiroz, A.C. 2002. Análise de alimentos: métodos químicos e biológicos. UFV. Viçosa. $235 \mathrm{pp}$.

Silva, E.C.; Ferreira, M.A.; Ramos, A.O.; Pessoa, R.A.S.; Félix, S.C.R.; Gomes, L.H.S.; Conceição, M.G. e Costa, S.B.M. 2009. Comportamento 


\section{CARVALHOETAL.}

ingestivo de ovinos alimentados com diferentes fontes de fibra em dietas à base de palma forrageira. http://www.eventosufrpe.com.br/ jepex2009/cd/resumos/R1035-1.pdf (10/08/ 2012).

Sniffen, C. J.; O'Connor, J.D.; Van Soest, P.J.; Fox, D.G. and Russel, J.B. 1992. A net carbohydrate and protein system for evaluating cattle diets; II. Carbohydrate and protein availability. J Anim Sci, 70: 3562-3577.
Valadares Filho, S.C.; Paulino, P.V.R. e Magalhães, K.A. 2006. Exigências nutricionais de zebuínos e tabela de composição de alimentos BR - corte. UFV, DZO. Viçosa. 142 pp.

Zambom, M.A.; Santos, G.T.; Modesto, E.C.; Alcalde, C.R.; Gonçalves, G.D.; Silva, D.C.; Silva, K.T. e Faustino, J.O. 2001. Valor nutricional da casca do grão de soja, farelo de soja, milho moído e farelo de trigo para bovinos. Acta Sci, 23: 937943. 